\title{
Age Assessment Practices by Dental Practitioners in Selected County Hospitals in Kenya
}

\author{
Eunice Njeri Kihara ( $\nabla$ ekihara@uonbi.ac.ke) \\ Jomo Kenyatta University of Agriculture and Technology \\ Simon Karanja \\ Jomo Kenyatta University of Agriculture and Technology \\ Peter wanzala \\ Kenya Medical Research Institute \\ Evelyn Gacheri Wagaiyu \\ University of Nairobi
}

\section{Research Article}

Keywords: age assessment, dental age, tooth maturity

Posted Date: August 24th, 2021

DOI: https://doi.org/10.21203/rs.3.rs-827606/v1

License: (c) (1) This work is licensed under a Creative Commons Attribution 4.0 International License. Read Full License 


\section{Abstract \\ Background}

Globally, individuals who do not possess authentic documentation of date of birth may require age assessment before accessing certain rights or facing legal consequences. The determination of age requires customization and a systematic multidisciplinary approach. Hence, professional and human rights organizations have established relevant guidelines. In Kenya, there is lack of a documented local policy on age assessment; nevertheless, the dentists working in public hospitals often receive patients for age assessment. In order to improve on local practices, there is need to investigate current age assessment procedures. Therefore, the objective of this study was to look at the age assessment methods in use currently.

\section{Methods}

The study design was cross-sectional. Data was collected prospectively from new patients who visited eight (8) selected public dental health facilities for age assessment during the study period 20192020.Patients were sampled through convenience sampling from randomly selected hospitals. Study variables included gender, estimated age and age assessment methods. The data was analysed using the Statistical Package for the Social Sciences (SPSS) version 20. The statistical significance was tested by Chi-square test.

\section{Results}

The study included 316 patients, 186(58.9\%) males and 130(41.1\%) females. The average age was 19.42 \pm 12.33 years, with a range of $1.5-79$ years. There were significantly $\left(X^{2}(7)=39.883, p=0.000\right)$ more children $(248,78.5 \%)$ than adults $(68,21.5 \%)$. The age was assessed through examination of presented documents, social history and review of eruption patterns. There was significant use of dental panoramic radiographs $(210,66.5 \%)$ to review root formation $\left(X^{2}(7)=164.991, p=0.000\right)$. Unspecified tooth maturity tables were used to deduce the dental age.

\section{Conclusion}

Age assessment was mostly indicated for children aged 18 years and below. Both non-medical and medical methods were applied in age assessment though devoid of any structured processes. Observation of eruption patterns and use of dental panoramic images to assess developing teeth were utilized in most patients. The dental age was assessed through the use of unspecified tooth maturity tables. There is need for further training on application and limitations of age estimation methods as well as development of a national protocol so as to ensure equality and provision of evidence based age assessment services. 


\section{Background}

Age assessment is an ancient practice which was widely utilized before introduction of birth registration. Age had to be determined for example prior to recruitment into military and other employment opportunities as well as in handling crimes. Globally, the need for age assessment continues to increase due to rising of diverse social, economic and political challenges ${ }^{1-3}$ to this end various approaches have been applied which includes the use of non-medical and medical methods. The use of dentition to determine age of living individuals is one of the medical methods which have been in use since 19th century. In order to improve on precision, there has been advancement from mere observation of eruption patterns of teeth to radiographic analysis of mineralization levels of developing teeth. This has resulted into publication of several tooth maturity charts and tables as well as quantitative and qualitative scoring methods. ${ }^{4-7}$ Determination of dental age in living adults has been achieved through radiological analysis of the size of the pulp cavity and morphological analysis of attrition of enamel and changes in periodontal attachment. $^{8-11}$

Age estimation in growing children and young people has been widely researched since they form the largest population that requires age assessment services due to diverse age related socioeconomic and legal needs. The United Nation Convention on the rights of the Child, Kenya being a member state, provides general guidelines that need to be considered while undertaking age assessment so as not to violate children's rights. Implications of assessing the children as adults includes placement in adult detention facilities or failure to provide them with necessary protection as noted recently in Spain by the Committee on the rights of children. ${ }^{12,13}$ Hence, the choice of age estimation method and its application is paramount. Various professional and human right organizations and agencies have also developed extensive guidelines on age assessment especially for unaccompanied children. ${ }^{14-16}$ In general, the determination of age requires customization and a systematic multidisciplinary approach which can be time consuming and may involve application of either non-medical assessment with or without medical examinations. However, the least intrusive method should be applied while maintaining a person's dignity. When the analysis of available evidence is not adequate, psychological assessment can be done but if doubt remains then restricted physical examination is recommended. Imaging of bone and/or teeth may be done depending on the local protocol while remembering to keep the radiation as low as reasonably possible. ${ }^{5,16-19}$

The Registration of Persons Act of Kenya allows one to prove their apparent age prior to issuance of various registration documents. Among the acceptable documents is a birth certificate, church baptismal card or age assessment certificate. Notably, age assessment certificate should be issued by a government employed medical officer of Health but the law does not dictate how the age should be determined. ${ }^{20}$ In this regard, the dental clinicians based in any government sponsored hospitals often receive requests for age assessment. Sometimes they are summoned by the court when the estimated age is rejected by the applicant or the judge.

Whereas, various countries such as Germany, Austria, United State of America and Norway countries have adopted their own comprehensive criteria for age estimation, there is hardly any documented data on age 
estimation protocols or practices in Kenya. $7,21,22$ In order to improve on local practices and establish evidence based procedures, there is need to investigate current age assessment practices. Therefore, the aim of this study was to assess the current utilization of age estimation methods by dental clinicians from selected health facilities in Kenya.

\section{Method}

The study design was cross-sectional. Data was collected prospectively from new patients who visited the dental health facilities for age assessment during the study period 2019-2020. Both adult and children patients were included in the study. Patients who were not referred for age assessment at the dental facility were excluded. Patients and or their guardians where applicable were interviewed by the research assistants and data entered in data collection forms. The data was collected from patients who had consented to undergo age assessment. Collected information included gender, estimated age as assessed by the dental clinician, methods used to assess age and types of radiographs that were utilized.

Patients were sampled from selected level 5 government hospitals which offered dental age estimation services among other oral health services. A level 5 government hospital is one that offers both training and clinical services including inpatient wards, dental, other specialties and various diagnostic services. Eight (8) hospitals were selected in total. Each hospital was selected from a different region in Kenya, namely, the eight former provinces (Central, Coast, Eastern, Nairobi, North Eastern, Nyanza, Rift Valley and Western Kenya). The hospitals were sampled through simple random sampling from a list provided by the Kenya Medical Practitioners and Dentist Council (KMPDC). There were a total of 41 level five government hospitals in the country according to the list provided by KMPDC. One hospital was selected randomly from the ones available in each region. Study participants were sampled through convenience sampling.

Authority to conduct the research was granted by the Kenyatta National Hospital/University of Nairobi (KNH/UON)-Ethics and Research Committee (ERC) (P104/02/2019), Ethical Review Committee of each Hospital and National Commission for Science, Technology \& Innovation (NACOSTI/P/20/1105 and NACOSTI/P/19/1105). The data was analysed using the Statistical Package for the Social Sciences (SPSS) version 20.The chi-square test $\left(X^{2}\right)$ was applied to assess the association between age assessment practices and other variables. The level of significance was set at a $p$-value of $₫ 0.05$.

\section{Results}

A sample of 316patients who visited the dental clinics for age assessment during the study period was enrolled in the study. There were significantly more males $(186,58.9 \%)$ who presented for age estimation compared to females $130(41.1 \%)$ females $\left(X^{2}(7)=44.712, p=0.000\right)$.

They had an average age of $19.42 \pm 12.33$ years, females $(19.94 \pm 14.19)$, males $(19.05 \pm 9.64)$ and a median age of 17 years. Majority were children aged 18 years and below $(248,78.5 \%)$ as compared to adults $(68,21.5)$. There was a significant difference in the age of presentation for age assessment $\left(X^{2}(7)=\right.$ $39.883, p=0.000)$. The age range was $1.5-79$ years. Majority of the patients were in the age group of 11 to 
20 years $(255,80.7 \%)$ whereby most were found to be between 16 and 19 years $(191,60.4 \%)$. They comprised of $186(58.9 \%)$ males and 130 (41.1\%) females (Tables 1 and 2). Most facilities received more male patients while one hospital received more female patients $(32,80 \%)$ when compared to the other facilities (Tables 1 and 2).

All the patients went through routine dental history and clinical examination. Their age was assessed through a multifaceted approach (Table 3). It included examination of any documents that were presented and interrogation of the social history so as to guide through the age assessment process. Additionally, erupted and non-erupted teeth were examined to reveal the eruption patterns. Majority of children and adults also had dental panoramic radiographs $(210,66.5 \%)$ undertaken. There was statistically significant use of radiographs for age estimation $\left(X^{2}(7)=164.991, p=0.000\right)$. There were 6 dental facilities which had dental panoramic imaging machines available within their facility while only one facility did not utilize radiographs for age assessment (Table 4). They were used to assess the level of tooth maturity especially the status of the closure of the root apices. No specific growth tables or charts were mentioned.

Table 1

Distribution of patients who visited for age assessment in selected facilities

\begin{tabular}{|llllll|}
\hline \multirow{2}{*}{ Region } & Gender & \multicolumn{3}{c}{ Age category } & Total \\
\cline { 2 - 5 } & Female & Male & Children & Adult & \\
\hline Nairobi & 10 & 30 & 29 & 11 & 40 \\
\hline Central & 12 & 28 & 31 & 9 & 40 \\
\hline Eastern & 20 & 18 & 29 & 9 & 38 \\
\hline Rift valley & 32 & 8 & 40 & 0 & 40 \\
\hline Coast & 21 & 19 & 25 & 15 & 40 \\
\hline North eastern & 16 & 24 & 22 & 18 & 40 \\
\hline Nyanza & 9 & 31 & 37 & 3 & 40 \\
\hline Western & 10 & 28 & 35 & 3 & 38 \\
\hline Total & 130 & 186 & 248 & 68 & 316 \\
\hline
\end{tabular}


Distribution of patients according to age groups

\begin{tabular}{|c|c|c|c|c|c|c|c|c|c|}
\hline \multirow[t]{2}{*}{ REGION } & \multicolumn{8}{|c|}{ AGEGROUP } & \multirow[t]{2}{*}{ Total } \\
\hline & $1-10$ & $11-20$ & $\begin{array}{l}21- \\
30\end{array}$ & $31-40$ & $\begin{array}{l}41- \\
50\end{array}$ & $\begin{array}{l}51- \\
60\end{array}$ & $\begin{array}{l}61- \\
70\end{array}$ & $\begin{array}{l}71- \\
80\end{array}$ & \\
\hline Nairobi & 0 & 32 & 2 & 3 & 1 & 0 & 1 & 1 & 40 \\
\hline Central & 0 & 32 & 1 & 0 & 0 & 3 & 0 & 4 & 40 \\
\hline Eastern & 4 & 34 & 0 & 0 & 0 & 0 & 0 & 0 & 38 \\
\hline $\begin{array}{l}\text { Rift } \\
\text { valley }\end{array}$ & 2 & 38 & 0 & 0 & 0 & 0 & 0 & 0 & 40 \\
\hline Coast & 2 & 17 & 0 & 12 & 3 & 3 & 3 & 0 & 40 \\
\hline $\begin{array}{l}\text { North } \\
\text { Eastern }\end{array}$ & 6 & 28 & 6 & 0 & 0 & 0 & 0 & 0 & 40 \\
\hline Nyanza & 1 & 39 & 0 & 0 & 0 & 0 & 0 & 0 & 40 \\
\hline \multirow[t]{2}{*}{ Western } & 3 & 35 & 0 & 0 & 0 & 0 & 0 & 0 & 38 \\
\hline & $18(5.7)$ & $255(80.7)$ & $9(2.9)$ & $15(4.75)$ & $4(1.3)$ & $6(1.9)$ & $4(1.3)$ & $5(1.6)$ & $316(100)$ \\
\hline
\end{tabular}

Table 3

Age assessment practices in selected health facilities

\begin{tabular}{|llllll|}
\hline Facility & $\begin{array}{l}\text { Evaluation of provided } \\
\text { documents }\end{array}$ & $\begin{array}{l}\text { Psychosocial } \\
\text { history }\end{array}$ & $\begin{array}{l}\text { Physical } \\
\text { growth }\end{array}$ & $\begin{array}{l}\text { Eruption } \\
\text { patterns }\end{array}$ & $\begin{array}{l}\text { Panoramic } \\
\text { radiograph }\end{array}$ \\
\hline Nairobi & Yes & Yes & No & Yes & No \\
\hline Central & Yes & Yes & No & Yes & Yes \\
\hline Eastern & Yes & Yes & No & Yes & Yes \\
\hline $\begin{array}{l}\text { Rift } \\
\text { valley }\end{array}$ & Yes & Yes & No & Yes & Yes \\
Coast & Yes & Yes & No & Yes & Yes \\
\hline $\begin{array}{l}\text { North } \\
\text { eastern }\end{array}$ & Yes & Yes & No & Yes & Yes \\
\hline Nyanza & Yes & Yes & No & Yes & Yes \\
\hline Western & Yes & Yes & No & Yes & Yes \\
\hline
\end{tabular}


Table 4

Utilization of dental panoramic radiographs in various age groups

\begin{tabular}{|c|c|c|c|c|c|c|c|c|c|}
\hline \multirow{2}{*}{$\begin{array}{l}\text { Radiographic } \\
\text { investigation }\end{array}$} & \multicolumn{8}{|c|}{ Age group(years) } & \multirow[t]{2}{*}{ Total } \\
\hline & $\begin{array}{l}1- \\
10\end{array}$ & $\begin{array}{l}11- \\
20\end{array}$ & $\begin{array}{l}21- \\
30\end{array}$ & $\begin{array}{l}31- \\
40\end{array}$ & $\begin{array}{l}41- \\
50\end{array}$ & $\begin{array}{l}51- \\
60\end{array}$ & $\begin{array}{l}61- \\
70\end{array}$ & $\begin{array}{l}71- \\
80\end{array}$ & \\
\hline Radiographs done & 10 & 174 & 2 & 12 & 3 & 6 & 3 & 0 & 210 \\
\hline \multirow[t]{2}{*}{ No radiographs } & 8 & 81 & 7 & 3 & 1 & 0 & 1 & 5 & 106 \\
\hline & 18 & 255 & 9 & 15 & 4 & 6 & 4 & 5 & 316 \\
\hline
\end{tabular}

\section{Discussion}

A combination of both medical examinations and non-medical methods were utilized in assessing age across the country. Admittedly, the decision to apply any method is dependent on the age and circumstances of each individual hence variation in the application of the methods is expected. The assessment of availed documents and psychosocial history were utilized in all the study facilities though devoid of any structured protocol of doing it. This is an important part of the physically-non-invasive method of assessing age which is deemed sufficient if it proofs one's age beyond any reasonable doubt. To this end, expertise in psychology and social work is essential. Besides, patients who require age estimation could be experiencing psychologically traumatizing events and therefore require to be handled carefully and professionally without exerting undue stress. Therefore, this may be a challenge to the dentist who may not be adequately trained to apply such knowledge. ${ }^{16,23,24}$ Moreover, the European Asylum Support Office (2018) recommends that any method which is applied should be interpreted by experts who have been trained to apply that particular method. Thus, there is need to train the dentists in this regard while looking into future possibilities of incorporating the psychologists and social workers in age assessment.

The exclusive analysis of eruption patterns without imaging was utilized in some patients but dental growth charts used to derive the age were not commonly specified. There are recommendations that methods used to determine age should be specified, their accuracy and reliability should be noted and a margin of error provided in the age assessment report. ${ }^{25}$ This highlights the need to develop local guidelines on age assessment which would additionally help to absolve the clinicians when the age assessment is challenged in a court of law. The dental clinicians are likely to use familiar charts that were provided during dental training or any other that is easily accessible whether online or in print media. There is paucity of local publications on eruption patterns and the most popular local study is one published three (3) decades ago based on teeth of Kenyan Africans and Asians. ${ }^{26,27}$ Due to the secular trends of growth resulting from changing diet and other environmental factors, there is need for current data on eruption patterns in Kenya In addition; ethnicity has been found to play a role in the development of third molars. ${ }^{28-31}$

Interpretation of dental age through observation of eruption patterns should be done cautiously following a thorough dental examination since local or exogenous factors such as tooth crowding, early extraction, 
dental impaction and nutritional status have been found to either delay or hasten tooth eruption. ${ }^{32}$ Therefore, a reasonable margin of error should also be provided. Notably, most patients who sought age assessment services were above 16 years; hence, mostly the status of the eruption of the third molars would be utilized to determine age. Clinically missing third molars due to impaction, extraction or congenital anodontia may lead one to assess an individual as underage. This may cause future disputes with dire legal implications especially when the same individual is assessed after a few years and the age remains the same or when authentic evidence of age is reproduced later in the court of law. Therefore, a dental panoramic image is indicated as it's also medically justified. ${ }^{33}$

Most patients had panoramic dental radiographs taken which played a role in determining the age through assessment of mineralization levels of developing tooth. A similar practice was utilized in 17 European countries; however, they were combined with hand and wrist x-rays to assess age of asylum seeking individuals. ${ }^{16}$ In this study, the dentists still utilized unspecified atlas methods to allocate age based on the level of tooth maturity. Nevertheless, tooth developmental charts/tables do not provide an age range while they are not gender specific. Newly developed age estimation methods utilise radiographs in calculating age through either utilization of tooth measurements or through staging of maturity levels and assigning a maturity score 4,5 Such mathematical methods are advantageous since they meet the criteria for age estimation methods as outlined by Ritz-Timme et al. ${ }^{23}$ but they were not applied in the selected study centers. Therefore, further training is required on how to utilize such methods. In addition, the methods need to be validated in the Kenyan population since they have been developed using other populations. The validation of Willems method has been assessed in Kenya using a small study population and was found to be accurate, however, validation with a larger sample is still required. ${ }^{34}$

Despite having numerous radiographic age estimation methods, their credibility is still disputed since not all individuals grow at the same rate, hence, the methods may lead to over- or underestimation of age of some individuals leading to unfair judgment. ${ }^{35}$ To this end, The International Society for Social Pediatrics and Child Health in Geneva and British Dental Association have discouraged their professionals from assessing age of asylum seekers. This is meant to protect the asylum seekers whose tooth maturity reference data is hardly documented. Further; the use of ionizing radiation for the absolute purpose of age assessment is still disputed in the United Kingdom. Nevertheless, some dental professionals support their utilization since they are associated with low ionizing radiation and are only utilized on individuals whose age is disputed. ${ }^{36,37}$ Hence, the need for each country to evaluate their own practices and establish acceptable guidelines that will benefit those seeking age assessment services. It is recommended that the age of an individual should be determined using a reference population in which the person belongs and the most accurate method for a particular population should also be utilized. 7,14,38 Therefore, a local study on tooth eruption and developmental stages of mineralization is highly recommended. This ensures reduction of the racial and environmental influence, hence, improving accuracy and limiting the margin of error in the estimated age.

The study found that there was no utilization of any documented criteria of age assessment. Therefore, there is need to develop a national protocol so as to provide equality in provision of age assessment 
services and hence, avoid legal implications or violation of human rights. An online age assessment computer application is strongly recommended. Collaboration with international professional organizations or agencies that are highly experienced in age assessment is paramount. The results provide a general outlook of age assessment practices in Kenya but may not be generalized since they were based on selected hospitals. Recall and non response bias was noted where tooth maturity tables and charts referred to during age assessment were not specified. The personal and legal implication of the given age was not assessed and additional studies are recommended.

\section{Conclusion}

Dentists in Kenya receive patients for age assessment. The service is mostly sought by children aged 18 years and below. Both non-medical and medical methods were applied. Observation of eruption patterns and use of dental panoramic images to assess developing teeth were utilized in most study centers. The dental age was assessed through the use of unspecified growth tables. There is need for further training on application and limitations of age estimation methods as well as development of a national protocol so as to ensure equality in provision of quality age assessment services.

\section{List Of Abbreviations}

SPSS - Statistical Package for the Social Sciences

KMPDC - Kenya Medical Practitioners and Dentist Council

$\mathrm{KNH}$ - Kenyatta National Hospital

UON - University of Nairobi

ERC - Ethics and Research Committee

NACOSTI - National Commission for Science, Technology \& Innovation

\section{Declarations}

- Ethics approval and consent to participate - Authority to conduct the research was granted by the Kenyatta National Hospital/University of Nairobi (KNH/UON)-Ethics and Research Committee (ERC) (P104/02/2019), Ethical Review Committee of each Hospital and National Commission for Science, Technology \& Innovation (NACOSTI/P/20/1105 and NACOSTI/P/19/1105).

- Consent for publication - the manuscript does not contain any individual person's data in any form

- Availability of data and materials - The datasets used and/or analysed during the current study are available from the corresponding author on reasonable request.

- Competing interests-"The authors declare that they have no competing interests" in this section.

- Funding - The research was not funded 
- Authors' contributions - EK, SK, PW and EW participated in writing the protocol for ethical review. EK collected the data and wrote the manuscript under the guidance of SK, PW and EW. "All authors have read and approved the manuscript".

- Acknowledgements - We appreciate all the hospitals which participated in the study and the research assistants who assisted in collecting data

\section{References}

1. Internal Displacement Monitoring Centre (IDMC) 2019.https://www.internal-displacement.org/ Accessed 13 May 2021

2. United Nations Office on Drugs and Crimes (UNODC) https://www.unodc.org/ Accessed 13 May 2021.

3. Violence against Children Survey (VACS). 2019. https://www.unicef.org/kenya/reports/The-2019Violence-Against-Children-Survey Accessed: 13 May 2021

4. Cameriere R, Ferrante L, Liversidge HM, Prieto JL, Brkic H. Accuracy of age estimation in children using radiograph of developing teeth. Forensic Science International. 2008;176:173-177.

5. Willems G. A review of the most commonly used dental age estimation techniques. J ForensicOdontostomatol, 2001;19:9-17.

6. Priyadarshini C, Puranik M P, Uma S R. Dental Age Estimation Methods: A Review. Int J Adv Health Sci 2015;1(12):19-25

7. Senn DR. and Weems RA. Manual of forensic odontology. 5th ed. United States: CRC Press, Taylor and Francis Group; 2013.

8. Kvaal SI, Kolltveit KM, Thompson IO, Solheim T. Age estimation of adults from dental radiographs. Forensic Scilnt. 1995;74:175-185.

9. Solheim T. A new method for dental age estimation in adults. Forensic Scilnt. 1993;74:137-147.

10. Verma M, Verma N, Sharma R, Sharma A. Dental age estimation methods in adult dentitions: An overview. J Forensic Dent Sci. 2019;11(2):57-63. doi:10.4103/jfo.jfds_64_19

11. Asif MK, Nambiar P, Mani SA, Ibrahim NB, Khan IM, Lokman NB. Dental age estimation in Malaysian adults based on volumetric analysis of pulp/tooth ratio using CBCT data. Leg Med (Tokyo). 2019 Feb;36:50-58. doi: 10.1016/j.legalmed.2018.10.005. Epub 2018 Oct 21. PMID: 30415192.

12. United Nations Convention on the rights of the child (UNCRC). 1990. https://www.ohchr.org/EN/Professionallnterest/Pages/CRC.aspx Accessed 4 May 2021].

13. Office of the High Commissioner for Human Rights (OHCHR). 2020. Spain's age assessment procedures violate migrant children's rights, UN committee finds.

https://www.ohchr.org/EN/NewsEvents/Pages/DisplayNews.aspx?NewsID=26375\&LangID=E Accessed 4 May 2021.

14. Unaccompanied Asylum Seeking Child (UASC): Age Assessment Guidance. 2020. https://northwestrsmp.org.uk/resources/children/uasc-age-assessment-guidance/ [Accessed: 4 May 2021]. 
15. Association of Directors of Children Services (ADCS) and Home Office Age Assessment Joint Working Guidance: 2015.

http://adcs.org.uk/assets/documentation/age_assessment_joint_working_guidance_april_2015.pdf Accessed 16 March 2021

16. European Asylum Support Office (EASO) practical guide on age assessment, $2^{\text {nd }} 2018$. https://easo.europa.eu/sites/default/files/easo-practical-guide-on-age-assesment-v3-2018.pdf Accessed 6 June 2021

17. United Nations Children's Fund (UNICEF). (2013). Age Assessment: A Technical Note. http://www.refworld.org/docid/5130659f2.html. Accessed: 11 July 2016.

18. Whaite E. Essentials of Dental radiography and radiology. 3rd ed. Churchil Livingstone; 1993

19. Dvorak J, George J, Junge A, Hodler J. Application of MRI of the wrist for age determination in international U-17 soccer competitions. British Journal of Sports Medicine. 2007;41(8):497-500. http://doi.org/10.1136/bjsm.2006.033431

20. Registration of Persons Act. 2012. (Cap 107, Laws of Kenya) (Section 16(4) 2(a) of the Registration of Persons Act of 2012). Kenyalaw.org. Accessed 15 March 2021.

21. Schmeling A, Dettmeyer R, Rudolf E, Vieth V, Geserick G. Forensic age estimation-methods, certainty, and the law. DeutschesArzteblatt International. 2016;113:44-50. DOI: 10.3238/arztebl.2016.0044

22. Koppenberg S. (2014). Unaccompanied minors in Austria -legislation, practices and statistics. [Online] Austria: International Organisation for migration. http://www.iomvienna.at. Accessed 17 June 2016.

23. Busler $D$, Cowell $K$, Johnson $H$, et al. Guidance to assist social workers and their managers in undertaking age assessments in England. Association of directors of children's services. 2015. http://adcs. org.uk/ assets/ documentation/ Age Assessment_Guidance_2015_Final. Pdf. Accessed 20 March 2021.

24. Kadir A, Battersby A, Spencer N, et al. Children on the move in Europe: a narrative review of the evidence on the health risks, health needs and health policy for asylum seeking, refugee and undocumented children. BMJ Paediatrics Open 2019;3:e000364. doi:10.1136/bmjpo-2018-000364

25. Ritz-Timme S., Cattaneo D., Collins MJ., Waite ER., Schutz, HW., Kaatsch HJ., Borrman HI. (2000). Age estimation: the state of the art in relation to the specific demands of forensic practice. International Journal of Legal Medicine. 2000;113:129-136.

26. Hassanali J, Odhiambo JW. Estimation of calendar age from eruption times of permanent teeth in Kenyan Africans and Asians. Ann Hum Biol 1982;9:175-177.

27. Hassanali J. The third permanent molar eruption in Kenyan Africans and Asians. Annals of human biology. 1985,12(6):517-523.

28. Olze A, van Niekerk P, Ishikawa T, Zhu BL, Schulz R, Maeda H. and Schmeling A, 'Comparative study on the effect of ethnicity on wisdom tooth eruption', Int J Legal Med. 2007;121:445-448.

29. Olze A, Schmeling A, Taniguchi M, Maeda H, van Niekerk P, Wernecke KD and Geserick G. 'Forensic age estimation in living subjects: the ethnic factor in wisdom tooth mineralization'. Int J Legal Med. 2004;118:170-173 
30. Esan TA, Schepartz LA. The WITS Atlas: A Black Southern African dental atlas for permanent tooth formation and emergence. Am J Phys Anthropol. 2018;166(1):208-218. doi:10.1002/ajpa.23424

31. AlQahtani SJ, Hector MP, and Liversidge HM. Brief Communication: The London Atlas of Human Tooth Development and Eruption. American Journal of Physical Anthropology 2010;142:481-490

32. Tandon S. Text book of pedodontics. 2nd ed. Hyderabad, New Delhi; 2008.

33. White SC. and Pharoah MJ. Oral Radiology: Principles and interpretation. 5th Ed. St Louis: Mosby Company; 2004.

34. Cadenas de Llano-Pérula M, Kihara E, Thevissen P, Nyamunga D, Fieuws S, Kanini M, \& Willems G. (2020). Validating dental age estimation in Kenyan black children and adolescents using the Willems method. Medicine, science, and the law, 25802420977379. Advance online publication. https://doi.org/10.1177/0025802420977379

35. Cole TJ. The evidential value of developmental age imaging for assessing age of majority. Ann Hum Biol, 2015;42(4):379-388

36. ISSOP Migration Working Group. ISSOP position statement on migrant child health. Child Care Health Dev. 2017;1- Accessed 16 march 2021 https://doi.org/10.1111/cch.12485

37. Roberts G, Lucas V, McDonald FS, Camilleri J, Jayaraman D. Davies \& Moze K. In our opinion. Br Dent J. 2017;222:918-921. https://doi.org/10.1038/sj.bdj.2017.537

38. Cunha E, Baccino E, Martrille L, Ramsthaler F, Prieto J, Schuliar Y, Lynnerup N, Cattaneo C. The problem of aging human remains and living individuals: A review. Forensic Science International. 2009;193:113 